\title{
Perinatal Outcome of Patients Undergoing Ex-Utero Intrapartum Therapy at the Fetal Therapy Units of Two Reference Centers in Bogota, Colombia
}

\author{
Saulo Molina-Giraldo ${ }^{1-3 *}$, Alexandra Coral-Rosero², Édgar Acuña-Osorio², José Luis Rojas-Arias², Martha Pinto-Quiñonez ${ }^{1-3}$, \\ Diana Alfonso-Ayala ${ }^{1}$, Nelly Santana-Corredor ${ }^{1-3}$, Mortimer Arreaza-Graterol ${ }^{1-3}$, Dairo Cera-Cabarcas ${ }^{1}$, José María Solano $^{1}$, \\ Diana Romero-Galvis', Bladimir Marín-Montoya ${ }^{2,4}$, Diana Arias-Fernandez ${ }^{2,4}$, Carlos Alberto Castro ${ }^{2}$, Armicson Felipe \\ Solano-Montero², and Jose L Perez-Olivo²
}

${ }^{1}$ Department of Obstetrics and Gynecology, Division of Maternal Fetal Medicine, Section of Fetal Therapy and Fetal Surgery Unit, and Division of Neonatology, Clinica Materno Infantil Colsubsidio, Hospital de San José, Bogotá, Colombia

${ }^{2}$ Fundación Universitaria de Ciencias de la Salud, Bogotá, Colombia

${ }^{3}$ Clínica de la Mujer, Unidad de Medicina Materno Fetal y Fetoscopia, Bogotá, Colombia

${ }^{4}$ Department of Paediatrics, Division of Neonatology, Hospital de San José, Bogotá, Colombia

*Corresponding author: Saulo Molina-Giraldo, Clínica de la Mujer, Unidad de Medicina Materno Fetal y Fetoscopia, Bogotá, Colombia, Tel: +57 6161799; E-mail: saulo.molina@urosario.edu.co; smolina@clinicadelamujer.com.co; smolina@fucsalud.edu.co

Received: 10 Sep, 2019 | Accepted: 04 Oct, 2019 | Published: 16 Oct, 2019

Citation: Molina-Giraldo S, Coral-Rosero A, Acuña-Osorio E, Rojas-Arias JL, Pinto-Quiñonez M, et al. (2019) Perinatal Outcome of Patients Undergoing Ex-Utero Intrapartum Therapy at the Fetal Therapy Units of Two Reference Centers in Bogota, Colombia. J Surg Open Access 5(5): dx.doi.org/10.16966/2470-0991.193

Copyright: (c) 2019 Molina-Giraldo S, et al. This is an open-access article distributed under the terms of the Creative Commons Attribution License, which permits unrestricted use, distribution, and reproduction in any medium, provided the original author and source are credited.

\section{Abstract}

Objective: To determine clinical characteristics in newborns with pulmonary or extra-pulmonary disease who undergo successful EXIT procedures at the Fetal Therapy Units of two reference centers in Bogota, Colombia.

Methodology: Descriptive case series study. Cases were defined as singleton pregnancies, with pulmonary or extra-pulmonary pathologies which caused obstruction in the fetal airway.

Results: Between 2006 and 2016, 54 patients underwent EXIT procedures. Results from prenatal diagnostic testing revealed the following: 27 patients $(50 \%)$ were diagnosed with diaphragmatic hernias, 15 patients (28\%) with cystic adenomatous malformation, four patients (7.4\%) with hydrothorax, three patients (5.5\%) with bronchopulmonary sequestrations, three patients $(5.5 \%)$ with cervical masses, one patient (1.8\%) with micrognathia, and one patient (1.8\%) with a Bronchogenic Cyst (QB). The average gestational age during the EXIT procedures was $37.2 \pm 2.54$ weeks (range 27-40 weeks). During ultrasound monitoring, 39 (61.1\%) cases of fetal complications were reported, eight (14.8\%) maternal complications during pregnancy, and seven (13\%) maternal surgical complications during the EXIT procedure. Average time of EXIT procedures was $10.8 \pm 5.29$ minutes (range 5-40 minutes) with an average hospital stay of $9.1 \pm 8.5$ days (range 1-39 days). The neonatal mortality rate was $60.3 \%$ (32/53 patients).

Conclusion: The EXIT procedure guarantees an effective transition into the postnatal environment, considerably increasing the chances of survival for the fetus by re-treating a potential emergency into a controlled state.

Keywords: Airway management; Placental circulation; Fetal monitoring; Therapy

\section{Introduction}

Ex-utero Intrapartum Treatment procedure (EXIT) is a fetal transition therapy that sustains placental circulation until the airway is confirmed in fetuses with intrinsic obstruction or extrinsic airways. In this state, adaptation and neonatal resuscitation can be achieved [1], allowing a real emergency to be converted in to urgency by reducing rates of perinatal mortality and morbidity $[2,3]$.

The EXIT procedure was first performed in 1997 and was initially developed to reverse the tracheal occlusion in fetuses with Congenital Diaphragmatic Hernias (CDH) [4]. Causes for performing the EXIT procedure have increased over time. Presently, it is still performed in $\mathrm{CDH}$ cases as well as ensuring the care of the fetal-placental circulation in intrinsic or extrinsic airway fetal pathologies which can impede ventilation at birth [5]. It is also applied in cases where neonatal reanimation may be at risk, as in a fetus with pulmonary masses, neck masses, congenital upper airways obstruction syndrome, intrathoracic masses, and unilateral pulmonary agenesis [6].

The EXIT procedure guarantees the uteroplacental gas exchange achieving hemodynamic stability under severe conditions of airway compression in the fetus, therefore, maximizing the chances of neonatal survival [3]. It is an innovative and promising technique in the initial approach to multiple neonatal pathologies. Nevertheless, the study as described so far has not created a regional characterization of patients undergoing the EXIT procedure. It has not reflected their 
prenatal and postnatal behavior nor the impact of this practice on neonatal morbidity and mortality in our environment [3,7,8-12].

The aim of this study is to determine the clinical characteristics in newborns with pulmonary or extra-pulmonary diseases that underwent the EXIT procedure at a Fetal Therapy Unit (FTU) at either of the two reference centers in Bogota, Colombia.

\section{Materials and Methods}

A descriptive case series study was performed. Some patients were comprised of singleton pregnancies, with pulmonary or extrapulmonary pathologies that compromised the fetal airway. These patients were diagnosed prenatally and received prior monitoring by Maternal-Fetal Medicine (MFM) while undergoing the EXIT procedure at the FTU of Hospital San José and Clínica Materno Infantil de Colsubsidio of Bogota (Colombia) from 2006 to 2016.

Patients with sonographic suspicions and genetic diagnoses of aneuploidy, an associated malformation which is considered incompatible with life and multiple gestations were excluded. Sociodemographic, clinical (gynecological and obstetric), ultrasound (prenatal), intraoperative (maternal and fetal), maternal complications, and neonatal immediate postpartum periods were measured. As a result, the ratio of correct sonographic diagnoses versus postnatal findings was established.

Data was collected from clinical records of each FTU and from prospective identifications of cases referred by the specialists at the two reference centers. Rigorous prenatal monitoring of each case was done by MFM medical specialists at each unit. All patients that were identified prenatally by fetal ultrasound and Magnetic Resonance Imaging had appropriate diagnoses. Stringent records of fetal growth and variables were collected in accordance with institutional protocol for each disease (AFI-Amniotic Fluid Index, CVR-Congenital Pulmonary Airway Malformation Volume Ratio, LHR-Lung Area to Head Circumference Ratio, fetal welfare, and hemodynamic variables).

Each case was presented maternal and perinatal boards a week before the EXIT procedure. All cases that met the criteria at the time described were included. The qualitative variables are presented as absolute and relative frequencies and quantitative measures of central tendency and dispersion, according to data distribution. Statistical analysis was implemented in Stata 12. This study was approved by an ethics committee for research on humans with approval codes ICP2015-003 of the Colsubsidio Center for Health Research and CEISH 022-2015 of the Fundación Universitaria de Ciencias de la Salud, Hospital de San José, where it was classified as an investigation with no potential risks.

A multidisciplinary team of specialists in MFM and fetal surgery, neonatology, anesthesiology, otolaryngology, critical and intensive adult care, psychiatry, and respiratory therapy, as well as nursing specialists with experience in obstetric and neonatal care, each contributed to their respective roles in each case study. During the EXIT procedure, the essential equipment required to perform: Fetal airway and neonatal ventilation, maternal hemodynamics and fetal monitoring, and neonatal monitoring and resuscitation $[12,13]$, was provided and located in the same operating room.

Delivery was scheduled as close to the end of gestation as possible. Indications and characteristics of the procedure, as well as possible maternal and fetal risks from having the EXIT procedure performed were explained to expectant women. With their prior informed consent, the procedures were done within the protocols of each institution.

Before starting the surgical procedure the following was completed: Anesthetic assessment, administration of prophylactic antibiotic, surgical pause, and checklist review. Maternal monitoring included pulse oximetry, continuous electrocardiography, noninvasive monitoring of blood pressure, capnography [14], urine output, and body temperature control. All patients received general anesthesia protocols according to Kern C, et al. [15], Schwartz DA, et al. [16], and Bouchard S, et al. [3]. Anesthetic rapid sequence induction [5] was performed following the recommendations of Schwartz DA, et al. [16] and Marques MV, et al. [17]. After fetal extraction active management of placenta extraction was also performed [18].

All laparotomies were performed through Pfannenstiel's suprapubic transverse incision with the exception of patients with previous cesarean incisions that had median infraumbilical. Transperitoneal segmental hysterotomy was performed with electrocautery. Hysterotomy with electrocautery is completed to the right and left

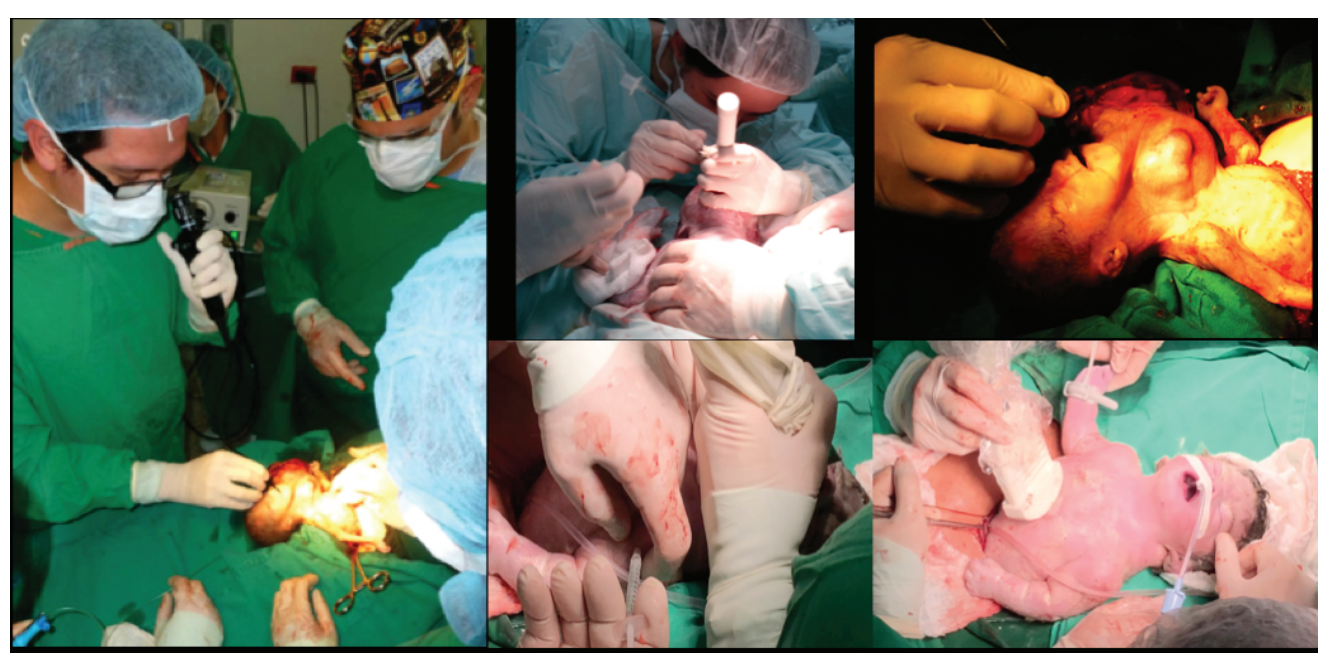

Figure 1: Fetal tracheal intubation under the support of the placenta during Ex-Utero Intrapartum Therapy (EXIT). 
sides respectively between two Rochester clamps while attempting to not compromise the amniotic membranes. The uterine cavity is then entered and the procedure carries onto fetal extraction to the upper third of the thorax and upper extremities ensuring reduction of nuchal cords. Amnioinfusion of normal saline pre-warmed to 37 degrees Celsius [14] was created, to ensure the stabilization of the proper amount of fluid in the uterine cavity (to avoid compression of the umbilical cord) and fetal body temperature.

To perform adequate fetal monitoring real time echocardiography was done similarly, pulse oximetry was performed throughout the procedure. Oxygen saturation and peripheral venous access were obtained. The fetus was medicalized with atropine intramuscularly (right shoulder) according to fetal heart rate $(0.1 \mathrm{mg} / \mathrm{kg})[14,16]$, with a maximum of three doses. According to the requirements of the procedure, fetal anesthesia was reinforced with an intramuscular injection of fentanyl $(15 \mathrm{mg} / \mathrm{kg})$ [14,19] and a muscle relaxant: vecuronium $(0.1 \mathrm{mg} / \mathrm{kg}) \quad[12,14]$. With stable fetal hemodynamic parameters, otolaryngology accessed the fetal airway through direct laryngobronchoscopy in certain cases. Most, however, were intubated by neonatology through indirect laryngoscopy only (Figure 1) [3].

The procedure carries onto fetal extraction to the upper third of the thorax and upper extremities. Echocardiography in real time, oxygen saturation and a peripheral venous access were created. With stable fetal hemodynamic parameters, otolaryngology accessed the fetal airway through direct laryngobronchoscopy in certain cases, while most were intubated by neonatology through indirect laryngoscopy only. Also note that it is possible to administer some intramuscular medications to the fetus if necessary.

No case required use of rigid bronchoscopy or tracheotomy. Subsequently, the cord was ligated, and the newborn entered neonatology monitoring in accordance with the relevant behavioral characteristics of their underlying disease.

Fetal management was dependent on the clinical context of each case. During the neonatal adaptation, the following variables were taken into account: temperature control, oxygenation, immediate ventilation ensuring the airway through endotracheal intubation during EXIT, and circulatory surveillance with continuous noninvasive monitoring (pulse oximetry in right hand and continuous echocardiogram) and subsequently invasive as required [13].

\section{Results}

In the period between 2006 and 2016, 54 patients underwent the EXIT procedure. The range of maternal age was between 14 and 41 years. The general characteristics of the pregnant population are presented in table 1 .

Of the fetuses undergoing the EXIT procedure, 35 (64.8\%) were male and $18(33.3 \%)$ female. The average gestational age at the time of EXIT was $37.2 \pm 2.54$ weeks (range 27-40 weeks). Eleven (20.3\%) patients were born preterm ( $<37$ weeks), four $(7.4 \%)$ were born at week 36 , two $(3.7 \%)$ were born at week 35 , two (3.7\%) at week 33 , and three $(5.5 \%)$ were extreme preterm deliveries performed in weeks 29 , 28 and 27 , respectively.

The entry into the uterine cavity did not have to be modified, since no placentas on the segment or area of incision were found. One case required the use of the external cephalic version of delivery for breech presentation. Fetal heart rate intra-EXIT averaged $137.9 \pm 23$ beats per minute (60-165 beats per minute). Fetal oxygen saturation through saturometry was on average $68 \pm 10.6 \%$ (range 50\%-96\%), and the average birth weight was $2830 \pm 612$ grams (range 905 grams-4500 grams).
Postnatal fetal variables were calculated on a total number of 53 cases (due to a newborn still hospitalized at the time of data analysis). The fetal mortality rate under the support of the placenta was $1.8 \%$ $(n=1)$. There were no fetal complications related to EXIT.

The average hospital stay was $9.1 \pm 8.5$ days (range 1-39 days), with mechanical ventilation of $5.01 \pm 4.9$ days (range 1-23 days), and the stay in the neonatal intensive care unit at $6.44 \pm 6.22$ days (range 1-26 days). Of the total number of newborns, 92.4\% ( $\mathrm{n}=49)$ had comorbidities during hospitalization, mainly respiratory type. The percentage of overall neonatal mortality (death during the first 30 days postnatal) was $60.3 \%$ (32/53 patients). Eight patients (15\%) died within the first 24 hours of life.

Table 1: Epidemiological characteristics of the pregnant population.

\begin{tabular}{|c|c|}
\hline & n (\%) \\
\hline $\begin{array}{l}\text { Average maternal age } \pm \text { SD (years) at } \\
\text { diagnosis }\end{array}$ & $27.1 \pm 5.7$ \\
\hline \multicolumn{2}{|l|}{ Gestations } \\
\hline One & $23(42.5)$ \\
\hline Two & $17(31.4)$ \\
\hline Three & $9(16.6)$ \\
\hline Four & $3(5.5)$ \\
\hline Five & $1(1.8)$ \\
\hline Six & $0(0)$ \\
\hline Seven & $1(1.8)$ \\
\hline \multicolumn{2}{|l|}{ Abortions } \\
\hline One & $9(16.6)$ \\
\hline Two & $2(3.7)$ \\
\hline Three & $1(1.85)$ \\
\hline None & $42(77.7)$ \\
\hline \multicolumn{2}{|l|}{ Births } \\
\hline One & $19(35.1)$ \\
\hline Two & $7(12.9)$ \\
\hline Three & $1(1.8)$ \\
\hline None & $27(50)$ \\
\hline \multicolumn{2}{|l|}{ Caesarean Births } \\
\hline One & $8(14.8)$ \\
\hline Two & $2(3.7)$ \\
\hline None & $44(81.4)$ \\
\hline \multicolumn{2}{|l|}{ Stillbirths } \\
\hline One & $4(7.4)$ \\
\hline None & $50(92.5)$ \\
\hline \multicolumn{2}{|l|}{ Ectopic pregnancy } \\
\hline One & $3(5.5)$ \\
\hline None & $51(94.4)$ \\
\hline \multicolumn{2}{|l|}{ Maternal history } \\
\hline $\begin{array}{l}\text { Other fetal malformations in previous } \\
\text { pregnancies }\end{array}$ & $3(5.5)$ \\
\hline Medical & $11(20.3)$ \\
\hline Toxic & $3(5.5)$ \\
\hline Allergic & $2(3.7)$ \\
\hline Pharmacologic & $3(5.5)$ \\
\hline Family (pathological in general) & $3(5.5)$ \\
\hline Relatives of other malformations & $3(5.5)$ \\
\hline $\begin{array}{l}\text { Mean gestational age } \pm \text { SD (weeks) (range) } \\
\text { at diagnosis }\end{array}$ & $26.2 \pm 6.2(11-37)$ \\
\hline
\end{tabular}

$\mathrm{n}$ : number of women participants

SD: Standard Deviation 
Sonographically, 24 hemidaphragm were of the left location (44.4\%) and three $(5.5 \%)$ of right location; One $(1.8 \%)$ cystic adenomatous malformation (CAM) type I, six (11.1\%) type II and eight (15\%) plus one additional type III (1.8\%) patient with hybrid mass; two (3.7\%) hydrothorax rights and two (3.7\%) left, two (4\%) patients with Intralobar Bronchopulmonary Sequestration (IBS), one (1.8\%) patient with Extralobar Bronchopulmonary Sequestration (EBS), three (5.5\%) cervical masses, one (1.8\%) fetus with micrognathia, and one $(1.8 \%)$ fetus with BC. No patients with Congenital High Airway Obstruction Syndrome (CHAOS) were reported.

The mean gestational age at EXIT of each condition above is outlined in table 2. Access to the fetal airway was established under the support of the placenta in all cases. Five (9.2\%) cases of difficult tracheal intubation were presented.

The mean surgical time from extraction of the fetal head to the cord clamping was 10.8 \pm 5.29 minutes (range 5-40 minutes) (Table 2).

Postnatally, there were 24 (45.2\%) cases of left hemidaphragm, three (5.7\%) cases of right hemidaphragm, and two (3.8\%) CAM type I, five (9.4\%) CAM type II, and three (5.7\%) CAM type III. There were also no cases of EBS, two (3.8\%) cases of right hydrothorax, one (1.9\%) of left hydrothorax, one (1.9\%) case of QB, one (1.9\%) case of pulmonary blastoma, and one (1.9\%) micrognathia case was diagnosed.

The neonatal pathology mortality rate was $100 \%$ for newborns with micrognathia, bronchogenic cysts, and right hydrothorax; 50\% (1/2) for hemidaphragm with a survival-to-hospital discharge of one patient with right hemidaphragm and two patients with left hemidaphragm. There were no deaths in newborns diagnosed with pulmonary blastoma and left hydrothorax (Table 3).

Eight (14.8\%) cases of maternal complications occurred during pregnancy. Premature Rupture of Ovular membranes (PROM) occurred in five $(9.26 \%)$ cases, all of them preterm with gestational ages between 27 and 36 weeks. Preterm labor in one (1.8\%) at 33 weeks, which required amnioreduction during fetal monitoring due to polyhydramnios. One $(1.8 \%)$ case of early onset preeclampsia at 28 weeks (fetus with cervical mass) and one case (1.8\%) of HELLP syndrome at 27 weeks.

Seven $(13 \%)$ cases of maternal surgical complications occurred during EXIT, and four (7.4\%) cases of all secondary to uterine atony postpartum hemorrhage. No patient required a blood transfusion, hysterectomy, or obstetric course with hemodynamic instability.

\section{Discussion and Conclusion}

The EXIT procedure allows controlled handling of the fetal airway $[19,20]$, while maintaining feto-placental circulation [19]. It decreases respiratory effort and prevents aerophagia [21], unlike conventional cesarean and vaginal deliveries [22], making it possible to maintain optimal fetal hemodynamics while running multiple additional procedures [19]. The EXIT procedure has been refined over time $[12,23]$ and today it is a useful and novel technique with significant advances in pharmacological anesthetic technique induction and uterine relaxation and management of fetal drug and monitoring fetal hemodynamics [12]; which allows it to be a safe procedure allowing the work group may make surgical decisions with adequate maternal and fetal stability [24].

Most studies schedule the EXIT procedure as close to term as possible to avoid problems of prematurity $[22,25]$. Some specialists have scheduled EXIT at 36 weeks in lung pathology and beyond 37 weeks for cervical pathologies [1]. The average gestational age of
EXIT in our series was $37.2 \pm 2.54$ weeks (range $27-40$ weeks) with an average similar to other similar series that were conducted at $34.6 \pm 3.5$ weeks (range 27-40 weeks) [14].

In a case series reported by Hedrick, the main indication for EXIT was handling the airway in fetuses with large neck masses or CHAOS [14]. Our greatest indication for EXIT was handling the airway in patients with lung disease: $50 \%$ and $28 \%$ with hemidaphragm CAM, where neck masses represented only $7.4 \%$, and no patient with CHAOS.

For fetuses with CAM in a series of five fetuses that were described at EXIT with a mean age 35.4 to 4.8 weeks (range 27-39 weeks) [8], the overall survival rate was $80 \%$ to $89 \%[8,14]$ with an average time of 63.8 minutes for the EXIT procedure (range 59-69 minutes) [14]. However, this includes the time used for resection of the lung mass. We describe a gestational age at EXIT for CAM at $36.2 \pm 3.1$ weeks (range 29-39 weeks) with most newborns born to term. With a shorter EXIT time, 8.6 \pm 2.05 minutes (range 5-13 minutes), no mass resection was performed to any patient and had a survival rate of $90 \%(1 / 10$ cases), similar to that reported in the literature.

For hemidaphragm in developed countries, survival rates can reach $64 \%$ to $80 \%$ to one year follow-up, with a described mean gestational age at EXIT of $37.5 \pm 1.3$ weeks (range $36-40$ weeks), and the largest gestational age reported for the pathologies brought to EXIT [21]. In our series, a gestational age of $38.1 \pm 0.8$ weeks (36-40 weeks) at EXIT was found, all greater than 36 weeks, most close to term ( $>37$ weeks), had a hospital stay of 6.1 \pm 93 days (range 1-39 days) and remained in the intensive care unit for $4.8 \pm 6.1$ days (range 1-26 days), which was less time than in previous reports in which that could correspond to early mortality (first 24 to 48 hours of life) of $92.5 \%$ (25/27 cases).

For cervical masses, many cases are complicated by polyhydramnios at high risk of preterm labor and PROM [1]. In our series, we found that in $16(25.8 \%)$ cases of polyhydramnios, most were associated with left hemidaphragm (6/16 cases) and CAM (4/16 cases) and 100\% had cervical masses $(n=3)$. The gestational age at EXIT in fetuses with neck masses varies between 34 and 36.1 weeks (range 31-40 weeks) [12,14].

In our series there are three cases of cervical masses with a survival rate of $33.3 \%$, lower than reported, births between 28 and 38 weeks (median 33 weeks), two cases required prior amnioreduction; which is less than the average recorded in the literature which had an EXIT time of $13.6 \pm 1.5$ minutes (range 12-15 minutes). This group recorded the only case of intra EXIT mortality (1.8\%), similar to the death rate reported in previous series in both percentage and fetal pathology associated [3].

We represent the largest series of pulmonary and extrapulmonary diseases reported in the literature and the only one developed in Colombia through a protocolled technique of uterine relaxation, analgesia, anesthesia and fetal monitoring. A surgical protocol with suprapubic transverse incision Pfannenstiel is posed, unlike the EXIT surgical protocol established from the criteria of a better surgical field with a medium infraumbilical incision [12].

The main limitations of the study are its descriptive nature and the sample size, in addition to the retrospective nature of some data collection. It is vital for future research to make a postnatal follow-up mid and long term, in order to establish a histopathologic correlation and to independently characterize the population who underwent the EXIT procedure.

In conclusion, the EXIT procedure is notoriously used to ensure an uteroplacentary gas exchange, with fetal hemodynamic stability 
Table 2: Number of patients, gestational age and mean Ex-utero intrapartum therapy (EXIT) time for each prenatal fetal pathology.

\begin{tabular}{|c|c|c|c|c|}
\hline Prenatal pathology & Number of patients (\%) & $\begin{array}{l}\text { Gestational age at diagnosis } \\
\quad \pm \text { SD (weeks) }\end{array}$ & $\begin{array}{c}\text { Gestational age at EXIT } \pm \text { SD } \\
\text { (weeks) range (weeks) }\end{array}$ & $\begin{array}{c}\text { Mean EXIT time } \pm \text { SD } \\
\text { (minutes) range (minutes) }\end{array}$ \\
\hline Diaphragmatic hernia & $\begin{array}{c}3.1 .3 \\
\text { Right: } 3(4.8) \\
\text { Left: } 25(43.3)\end{array}$ & $\begin{array}{c}29.4 \pm 5.1 \\
\text { Right: } 31.6 \pm 4.9 \\
\text { Left: } 28.3 \pm 6.4\end{array}$ & $\begin{array}{c}\text { Right: median } 37 \text { weeks } \\
\text { Left: } 38.1 \pm 0.8 \\
(36-40)\end{array}$ & $9.9 \pm 1.4(8-13)$ \\
\hline CAM & $15(24.2 \%)$ & $22.7 \pm 5.4$ weeks & $37 \pm 2.4(29-39)$ & $8.6 \pm 2.1(5-13)$ \\
\hline Hydrothorax & $4(6.5 \%)$ & Median 24.5 & $35 \pm 2.8(27-37)$ & $13.66 \pm 1.5(9-22)$ \\
\hline Cervical mass & $3(4.8 \%)$ & $25.6 \pm 5.2$ & $31 \pm 5.1(28-38)$ & $13.6 \pm 1.5(12-15)$ \\
\hline
\end{tabular}

SD: Standard Deviation

Table 3: Neonatal variables according postnatal pathology.

\begin{tabular}{|c|c|c|c|c|c|}
\hline Postnatal pathology & $\begin{array}{l}\text { Number of } \\
\text { patients (\%) }\end{array}$ & $\begin{array}{c}\text { Postnatal mortality } \\
\text { rate (\%) }\end{array}$ & $\begin{array}{l}\text { Hospitalization days } \pm \\
\text { SD (days) range (days) }\end{array}$ & $\begin{array}{l}\text { Mechanical ventilation days } \pm \\
\text { SD (days) range (days) }\end{array}$ & $\begin{array}{l}\text { NICU stay days } \pm \text { SD } \\
\text { (days) range (days) }\end{array}$ \\
\hline Diaphragmatic hernia & $\begin{array}{c}27(44.2) \\
\text { Right: } 3(4.9) \\
\text { Left: } 24(39.3)\end{array}$ & $92.5(25 / 27)$ & $6.1 \pm 9.3(1-39)$ & $5.01 \pm 4.9(1-23)$ & $4.8 \pm 6.1(1-26)$ \\
\hline CAM & $10(11.5)$ & $10(1 / 10)$ & $16 \pm 9.4(2-29)$ & $4.5 \pm 5.4(1-23)$ & $6.9 \pm 6.29(1-26)$ \\
\hline Hydrothorax & $\begin{array}{c}3(4.9) \\
\text { Law: } 2(3.3) \\
\text { Left: } 1(1.6)\end{array}$ & $66.6(2 / 3)$ & $2.3 \pm 0.57$ & $2.3 \pm 0.57$ & $3.36 \pm 1.52$ \\
\hline Cervical masses & $3(4.9)$ & $66.6(2 / 3)$ & $\begin{array}{l}8 \pm 4.2 \\
(8-14)\end{array}$ & $\begin{array}{c}8.5 \pm 7.0 \\
(3-14)\end{array}$ & $\begin{array}{c}9.5 \pm 6.3 \\
(5-14)\end{array}$ \\
\hline $\begin{array}{l}\text { Intralobar } \\
\text { bronchopulmonary } \\
\text { sequestration }\end{array}$ & $7(11.5)$ & $14.3(1 / 7)$ & $13 \pm 8.3$ & $6.57 \pm 5.5$ & $8.71 \pm 6.29$ \\
\hline Gastroschisis & 8 & 0 & $4.25 \pm 3.1(2-11)$ & $4.2 \pm 5(2-11)$ & $10.4 \pm 6(5-24)$ \\
\hline
\end{tabular}

SD: Standard Deviation

NICU: Neonatal Intensive Care Unit

CAM: Cystic Adenomatous Malformation

during a variety of surgical procedures performed to ensure the fetal airway and a successful transition to the postnatal environment, while providing the ability to maximize the chances of survival for the fetus. Due to the fact that performing an EXIT procedure diverges a potential emergency into a controlled situation, the overall fetal prognosis appears to be highly dependent on the etiology, prematurity, and possible fetal and neonatal complications.

\section{Acknowledgements}

We would like to thank the Departments of Gynecology and Obstetrics, Neonatal Intensive Care Unit, Pediatric Surgery, Anesthesiology, Radiology, Nursing, and Instrumentation Surgical of Hospital de San José, and the Clinica Materno Infantil de Colsubsidio, Bogotá, Colombia.

\section{Conflict of Interests}

The authors declare no conflicts of interest.

\section{References}

1. Cruz-Martínez $R$, Méndez A, Pineda-Alemán $H$, RebolledoFernández C (2015) Técnica EXIT (Ex Utero Intrapartum Treatment): indicaciones, limitaciones, riesgos y evolución a la técnica de intubación traqueal fetal endoscópica (FETI). Ginecol Obstet Mex 83: 58-65.
2. Quevedo FJL (2013) Plata Rueda. El Pediatra Eficiente. $7^{\text {th }}$ edition.

3. Bouchard S, Johnson MP, Flake AW, Howell LJ, Myers LB, et al. (2002) The EXIT procedure: experience and outcome in 31 cases. J Pediatr Surg 37: 418-426.

4. Mychaliska GB, Bealer JF, Graf JL, Rosen MA, Adzick NS, et al. (1997) Operating on placental support: the ex utero intrapartum treatment procedure. J Pediatr Surg 32: 227-230.

5. Laje P, Peranteau WH, Hedrick HL, Flake AW, Johnson MP, et al. (2015) Ex utero intrapartum treatment (EXIT) in the management of cervical lymphatic malformation. J Pediatr Surg 50: 311-314.

6. Hirose S, Harrison MR (2003) The ex utero intrapartum treatment (EXIT) procedure. Semin Neonatol 8: 207-214.

7. Gordon ED, Ferrá YMC (1999) Registro, incidencia y diagnóstico prenatal de las malformaciones congénitas mayores más severas. Rev Cubana Med Gen Integr 15: 404-408.

8. Hedrick HL, Flake AW, Crombleholme TM, Howell LJ, Johnson MP, et al. (2005) The ex utero intrapartum therapy procedure for high-risk fetal lung lesions. J Pediatr Surg 40: 1038-1043.

9. Svetliza J, Espinosa A, Gallo M, Palermo M, Deguer C, et al. (2009) Experiencia conjunta en Argentina y Chile con la técnica Símil-Exit para el tratamiento quirúrgico de la gastrosquisis. Revista Pediatría Electrónica 6: 132. 
10. Svetliza J, Palermo M, Espinosa AM, Gallo M, Calahorra M, et al. (2007) Procedimiento Símil-Exit para el manejo de gastrosquisis. Revista Iberoamericana de Medicina Fetal y Perinatal 1: 7-12.

11. Özgünen FT, Güleç ÜK, Evrüke iC, Demir SC, Büyükkurt $S$, et al. (2015) Fetal Orophary ngeal and Neck Tumors: Determination of the Need for Ex-Utero Intrapartum Treatment Procedure. Balkan Med J 32: 221-325.

12. Laje $\mathrm{P}$, Johnson MP, Howell LJ, Bebbington MW, Hedrick $\mathrm{HL}$, et al. (2012) Ex utero intrapartum treatment in the management of giant cervical teratomas. J Pediatr Surg 47: 1208-1216.

13. Wyckoff MH, Aziz K, Escobedo MB, Kapadia VS, Kattwinkel J, et al. (2015) Part 13: Neonatal Resuscitation: 2015 American Heart Association Guidelines Update for Cardiopulmonary Resuscitation and Emergency Cardiovascular Care. Circulation 132: S543-S560.

14. Hedrick HL (2003) Ex utero intrapartum therapy. Semin Pediatr Surg 12: 190-195

15. Kern C, Ange M, Morales, Peiry B, Pfister RE (2007) Ex utero intrapartum treatment (EXIT), a resuscitation option for intrathoracic foetal pathologies. Swiss Med Wkly 137: 279-285.

16. Schwartz DA, Moriarty KP, Tashjian DB, Wool RS, Parker RK, et al. (2001) Anesthetic management of the exit (ex utero intrapartum treatment) procedure. J Clin Anesth 13: 387-391.

17. Marques MV, Carneiro J, Adriano M, Lança F (2015) Anesthesia for ex utero intrapartum treatment: renewed insight on a rare procedure. Braz J Anesthesiol 65: 525-528.

18. Velez-Alvarez GA, Agudelo-Jaramillo B, Gomez-Davila G, ZuletaTobon JJ (2009) Código Rojo: Guía para el manejo de la hemorragia obtetrica. Revista Colombiana de Obstetricia y Ginecologìa 60: 3448.
19. George RB, Melnick AH, Rose EC, Habib AS (2007) Case series: Combined spinal epidural anesthesia for Cesarean delivery and ex utero intrapartum treatment procedure. Can J Anaesth 54: 218-222.

20. Suenaga M, Hidaka N, Kido S, Otera Y, Fukushima K, et al. (2014) Successful ex utero intrapartum treatment procedure for prenatally diagnosed severe micrognathia: a case report. J Obstet Gynaecol Res 40: 2005-2009.

21. Laveriano WV, Tacchino EH, Ríos OL, Girao MZ, Urquiaga WC (2015) Intubación endotraqueal intraparto en un feto con hernia diafragmática. A propósito de la primera cirugía fetal EXIT (ex-utero intrapartum treatment) en el Perú. Rev Peru Ginecol Obstet 61: 417421.

22. Diercks GR, Hartnick CJ, Bates SV (2015) Management of the critical airway when an EXIT procedure is not an option: A case report. Int J Pediatr Otorhinolaryngol 79: 2433-2437.

23. Harrison MR, Adzick NS, Flake AW, Vander Wall KJ, Bealer JF, et al. (1996) Correction of congenital diaphragmatic hernia in utero VIII: Response of the hypoplastic lung to tracheal occlusion. J Pediatr Surg 31: 1339-1348.

24. Barthod G, Teissier N, Bellarbi N, Viala P, Oury JF, et al. (2013) Fetal airway management on placental support: limitations and ethical considerations in seven cases. J Obstet Gynaecol 33: 787-794.

25. Liechty KW, Crombleholme TM, Weiner S, Bernick B, Flake AW, et al. (1999) The ex utero intrapartum treatment procedure for a large fetal neck mass in a twin gestation. Obstet Gynecol 93: $824-825$ 